\title{
Review on Trends in Machine Learning Applied to Demand \& Sales Forecasting
}

\author{
Ravindra Singh Sengar \\ M. Tech. Scholar \\ Department of M.E \\ Sagar Institute of Research \& Technology(SIRT) \\ Bhopal, India \\ ravisengar070193@gmail.com
}

\author{
Dr. Syed Faisal Ahmed \\ Associate professor \\ Department of M.E \\ Sagar Institute of Research \& Technology(SIRT) \\ Bhopal, India \\ faisalsyed08@gmail.com
}

\begin{abstract}
Supply Chain Management (SCM) is one of the new concepts put into practice in the commercial sector. At the beginning, Multinational Companies (MNCs) incorporated the supply chain into their structures, then other private conglomerates and local people defended these concepts. From the beginning, the main functions of SCM were the management of purchases and purchases, but subsequently SCM took the integrated form i.e. consists of sourcing, materials management, production support and sales management. Given the highly competitive market scenario, supply chain management is becoming the most important functional area of the business. Demand forecasting is affecting the success of Supply Chain Management (SCM), and the organizations which support them and are in the early stage of a digital transformation. In a near future it could represent the most significant change in the integrated SCM era in today's complex, dynamic, and uncertain environment. The ability to adequately predict demand by the customers in an SCM is vital to the survival of any business. In this paper a review is presented in which this problem is tried to solved by using various demand forecasting models to predict product demand for grocery items with machine learning techniques.
\end{abstract}

Keywords - Supply Chain Management, Demand forecasting, Warehouse, Sale Forecasting, Machine Learning.

\section{I.INTRODUCTION}

In the era of greater demand uncertainty, higher supply risk, and increasing competitive intensity, Supply Chain Management (SCM) excellence often depends on the organization's ability to integrate the entire spectrum of end-to-end processes of acquiring components or materials, converting them into finished goods, and delivering them to customers. Since such an ability can be improved by increased visibility across the endto-end SCM processes and many leading-edge organization's have attempted to enrich their information sources and share real-time information with Supply Chain (SC) partners [1]. SCM is the lifeblood of any business, impacting everything from the quality, delivery, and costs of business products and services to customer service and satisfaction to ultimately profitability and return on assets. The requirements and pressures on SC teams-including those for sustainability, cost efficiency, and disruption and risk mitigation-are increasing and growing in complexity. Unfortunately, most of the SC organization's are operating with systems built for another era.
They lack the transparency and visibility needed to predict better and mitigate disruptions and imbalance. As a result, SC organization's struggle to collect and make sense of an overwhelming amount of data scattered across different processes, sources and, systems. Under these conditions it is incredibly challenging to manage and monitor the complete SC, resulting in undesirable risk exposure, delays, disruptions, and as well as increased costs [2]. Thus SCM is becoming more information intensive, and its focus has been shifted toward the substitution of assets like inventory, Warehouses, transportation equipment with information. Recognizing the increasing significance of information to SC success, SC professionals have explored various ways to manage information better and leverage it to make better business decisions. Some of those ways include Artificial Intelligence (AI), Machine Learning (ML) has been in existence for decades but has not been fully utilized in the area of SCM.

\section{II.SUPPLY CHAIN MANAGEMENT}

The term 'SCM' refers to a network of organization's involved in generating value for the end customer in the form of products and services via upstream or downstream links in different processes and activities as shown in Fig. 1.

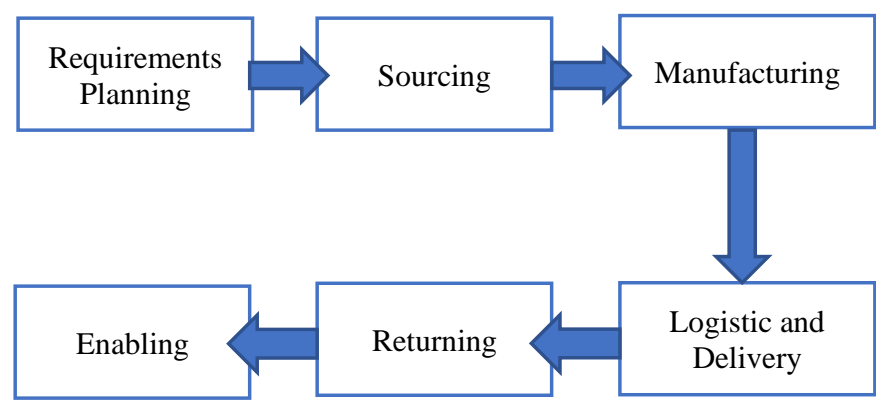

Fig. 1. Supply Chain Management process

SCM enables an organization to source the components and raw materials that are needed to create a service or product and deliver that service or product to customers [3].

The components involved in SCM are: 
1. Requirements Planning: Enterprises need to plan and manage all resources required to meet customer demands for their product or service. They also need to design their $\mathrm{SC}$ and then determine which metrics to use to ensure the $\mathrm{SC}$ is efficient, effective, delivers value to customers and meets enterprise goals [4].

2. Sourcing/Procurement: Companies must choose suppliers to provide the goods and services needed to create their product. After suppliers are under contract, SC managers use a variety of processes to manage and monitor supplier relationships. Key processes include ordering, managing inventory, receiving and authorizing supplier payments [4].

3. Manufacturing: SC managers coordinate the activities required to accept raw materials, manufacture the product, test for quality, the package for shipping and schedule for delivery. Most enterprises measure quality, production output, and worker productivity to ensure the enterprise creates products that meet quality standards [4].

4. Logistics and Delivery: This involves coordinating customer orders, dispatching loads, scheduling delivery, invoicing customers and receiving payments. It depends on a fleet of vehicles to ship products to customers. Many organization's outsource large parts of the delivery process to specialist organization's, particularly if the product has to be delivered to a consumer's home or requires special handling [4].

5. Returning: The supplier needs a responsive and flexible network to take back excess, unwanted and damaged products. If the product is defective, it must be scrapped or reworked. If the product is merely excess or unwanted, it must be returned to the warehouse for sale [4].

6. Enabling: To operate efficiently, the SC requires many support processes to monitor information throughout the SC and assure compliance with all regulations. Enabling processes include portfolio management, finance, HR, IT, facilities, product design, sales and quality assurance [4].

Latest technology can be beneficial and profitable in SCM. However, to get a budget or management support the fastest, the first question should be What needs to be improved in SCM right now? [5]. The following examples are as follows:-

1. Hard to plan for demand (demand forecasting) [5].

2. Excessive safety stocks and bullwhip effect [5].

3. Supplier unreliability [5].

4. Transport network unpredictability [5].

5. Looking at the real bottom line impact of supply chain decisions [5].

6. The forecasting of demands is one of the most challenging phases in SCM.

The current technologies for forecasting the demand are often presented the user with incorrect results, causing them to make severe financial mistakes. They cannot correctly understand the growing market patterns and market fluctuations, and this www.ijoscience.com hampers its power to calculates market trends and provide results accordingly adequately. What makes demand forecasting so challenging and complex? Rather than looking like a logical series of numbers, in today's business environment, we see demand like a pattern of partially constrained chaos. Demand is highly influenced by various internal and external factors that drive it up and down in ways that can not be understood by merely looking at a historical time-series of aggregated demand buckets. Instead, demand should be viewed as a complex series of indicators that can be nearly impossible to manage with traditional forecasting algorithms.

\section{FORECASTING LEVELS}

Determining the forecasting time horizon was identified above as a critical dimension of forecast development. Planners forecast the probable course of events that might occur over varying lengths of time. As illustrated in Figure 2, forecasting occurs on four levels.

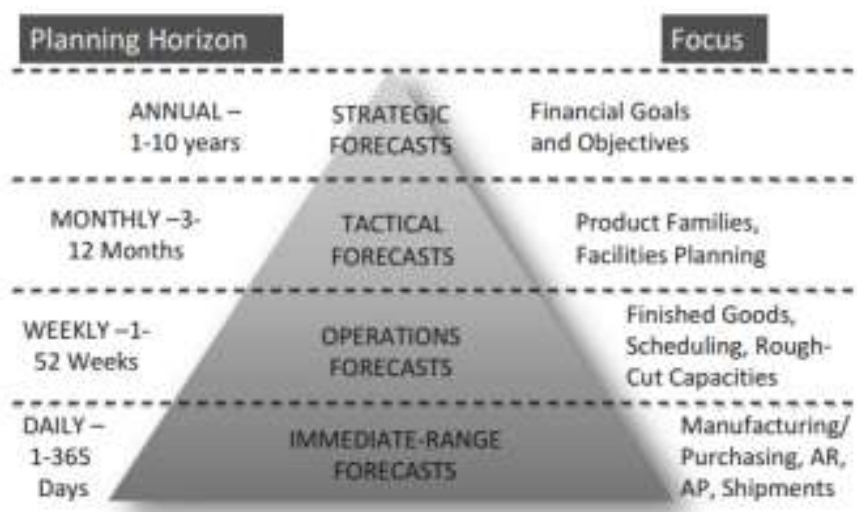

Fig. 2. Forecasting levels

The highest level is described as strategic forecasting. This level has a time horizon of at least 1 year and is used in the development of top management planning. Forecasts on the strategic level are usually stated in very general terms such as total sales dollars, return on assets, or some other aggregate set of values. Normally forecasts in this area use judgmental and correlation models where aggregate data is related to economic or marketplace indicators such as the gross national product, housing starts, and unemployment. Among the decisions associated with this level of forecasting are developing corporate goals and objectives; performing corporate capital budgeting; planning for facilities, equipment and other fixed assets; and structuring channel networks.

The next level, tactical forecasting, has a time horizon of 3 months to 1 year or longer and is normally applied to operations planning and control activities. Forecasts on the tactical level are usually stated in terms of aggregated values from sales revenues, output of product families, or some other measure. Classically, the forecast is built by aggregating the demand and forecasts for items into their respective product families. 
Forecasting decisions on this level impact sales, estimates of warehouse and transportation capacities, business area capital planning, production capacities, and contracting for public warehousing and transportation services. This level is concerned with forecasting product family level volumes.

Operations forecasting comprises the third level of forecast planning. This level consists of item-level forecasts normally decomposed from the family forecasts developed at the tactical level. Forecasts are normally concerned with the actual mix of end-items comprising product family forecasts. Forecasts in this level usually extend for at least a year into the future and appear in weekly time frames. Forecasting decisions on this level impact such activities as manufacturing scheduling, supplier scheduling, inventory procurement plans, transportation planning, materials handling equipment utilization, and detailed operating budgets.

Finally, immediate-range forecasting is used for everyday performance of ongoing activities. Examples include transportation scheduling, receiving, stock put away, shop floor and postponement scheduling, order filling, and accounts receivables and payables flow through. Each forecast level possesses its own unique characteristics relative to the most appropriate forecasting method and data required. It would be improper, for example, to employ a forecast method to calculate product demand on a weekly basis for the purpose of determining yearly aggregate sales income.

\section{IV.RELATED WORK}

Islek et al. (2017) [6] discussed demand forecasting is the process of constructing forecasting models to estimate the quantities of several products that customers will purchase in the future. When the warehouse and the number of products grow, forecasting the demand becomes dramatically hard. Most of the demand forecasting models rely on a single classifier or a simple combination of these models. In order to improve demand forecasting accuracy, author investigated several different classifiers such as MLP, Bayesian Network, Linear Regression and SVM analyzing their accuracy and performance. Moreover, we also studied some classifier combination techniques by approaching from demand forecasting perspective. In this paper, we propose a methodology to combine various forecasting models using neural networks rather for supporting demand forecasting. The proposed methodology is tested against single classifiers and classifier ensemble models using a real dataset.

HaixiaSang's et al. (2018) [7] this article presents a simulation approach to analyze the inventory problem of the rental housing chain. Unlike most products, the rental unit is a "traffic" type product and the inventory problem is complicated. This paper proposes a systematic and flexible process that effectively provides managers with critical decision-making tools to help them understand and validate inventory problems in the supply chain of rented accommodation. The proposed method takes inventory factors into account, such as the forecasting method, the time period, the initial inventory and the supply indicator. Furthermore, the procedure is applied to a real supply chain of rented accommodation to confirm its effectiveness. Furthermore, the proposed methodology has proved to be practical and effective in helping managers make ongoing decisions.

Christoph Flöthmann et al. (2018) [8] this exploratory study analyzes the careers of 307 supply chain managers (SCEs). Motivated by career theory, our ideas create new insights into the educational background and careers that lead to SCE positions. Based on an optimal matching analysis, we can distinguish six career models for SCEs. They differ in terms of previous work experience, training and time needed to reach a position of leadership. By characterizing the antecedents and career paths of CEMs, we show that Supply Chain Management (SCM) is a truly cross-functional profession. Our findings suggest that the former employee responsibility appears to be a more important recruitment criterion than the full experience of supply chain management. While $56 \%$ of managers had exemployee responsibilities, only $12 \%$ of the accumulated careers were actually spent in the SCM function.

Yuchen Weng et al. (2019) [9] proposed AutoRegressive Integrated Moving Average (ARIMA) model, back propagation (BP) network method, and recurrent neural network (RNN) method were tested to forecast the price of agricultural products (cucumber, tomato, and eggplant) in short term (several days) and long term (several weeks or months). A large-scale price data of agricultural products were collected from the website based on web crawler technology. Since ARIMA requires continuous and periodic data, it is suitable for small-scale periodic data. It gave good performance for average monthly data but not for daily data.

Mittal et al. (2019) [10] proposed a method of using Support Vector Regression (SVR) along with Particle Swarm Optimization (PSO). The retail sales data from the United States Census Bureau based on the monthly sales report for retail trade and food services report (2002) is used to test the performance of the system.

\section{V.MACHINE LEARNING IN DEMAND FORECASTING}

Before addressing the topic, it is important to clarify that Demand Forecasting is different from Sales Forecasting. The latter uses data that have been directly collected from the POS (Point of Sale), so it is subject to the effect of promotions or stock shortages. On the other hand, Demand Forecasting uses data where the effect of promotions or shortages has been corrected, with the objective of reflecting the actual market demand. Despite this subtle yet important difference, this paper will cover both concepts under a single term: Demand \& Sales Forecasting (D\&SF). D\&SF is one of the most important 
elements of any SC. It aims to coordinate all the SC partners by reducing the information lag between the final client and the ntier supplier. This provides several advantages, such as mitigation of the bullwhip effect, better resources and aggregate capacity planning, and reduction of stock shortages or oversupply costs [3]. The most widely known statistical techniques meant to forecast are also called traditional forecasting methods. Traditional forecasting methods are based on time series. This means they are applied under the hypothesis that the past demand can statistically estimate the future demand. Normally, these methods are easy to apply and present good performance in markets whose demand is mostly stable [1].

Unfortunately, this is not often the case: the demand also depends on exogenous factors that are not effectively represented by past values. For instance, on-demand ride services like UBER, Lyft or Didi Chuxing cannot estimate their demand by only relying on time series, they must take into account other elements like weather conditions (such as humidity, temperature, etc.), time of the day or day of the week [8].

To satisfy this need, other kinds of forecasting, known as causal modeling, proposes methods including exogenous elements such as macro-economic variables, weather conditions, marketing strategies, etc. [1]. These techniques allow to tackle the limits encountered in time series models. In that vein, ML itself could be considered as providing causal modeling because it can handle time series, categorical variables, fuzzy variables, text analysis, images, and other elements.

\section{VI.METHODOLOGY}

The Forecasting Process In the forecast development process, the following steps are normally performed:

1. Define the purpose of the forecast

2. Select the appropriate forecasting model(s)

3. Prepare the statistical components

4. Ensure the interaction of the firm's functional area managers

5. Execute the forecast

6. Track and maintain the forecast through timely and accurate feedback

Before a forecasting technique is chosen, forecasters first determine the purpose of the proposed forecast. In accomplishing this task planners are faced with three critical tasks. To begin with, they must match the proper forecasting method with the stated objectives of the firm's business units, ranging from long-term to short-term goals. Second, forecasters must utilize forecasting methods that are easily integrated to provide the enterprise with a comprehensive game plan that is supportive of both departmental, as well as, corporate performance targets. Finally, the forecasts must be capable of being communicated to supply chain partners. Failure to integrate the various forecasts not only through each business unit throughout the firm, but also externally with each trading partner, results in dysfunctional management decisions where business entities pursue separate objectives and potentially opposing measures of performance.

\section{CONCLUSION}

For the optimum balancing the supply chain in demand and sale better forecasting is important factor and by using Artificial Intelligence. Technique is easy and appropriate way to identify the realistic demand of future in various conditions by using previous data of demand and supply with inventory record by whole seller. Now a days Artificial Intelligence is a best method to enhance the supply chain management and recent research shows that for the deep learning process is introduced for optimizing various conditions in supply chain management.

\section{REFERENCES}

[1] Min, H.: Artificial intelligence in supply chain management: theory and applications. Int. J. Logist. Res. Appl. 26, 13-39 (2019).

[2] Stank, T., Scott, S., Hazen, B.: A savy guide to the digital supply chain. Appendix of Safeware: System Safety and Computers (2018). https://haslam.utk.edu/sites/default/files/GSCI.WhitePaper.Savvy .FINALFORISSUU.pdf. Accessed Jan 2019.

[3] Keunstler, B.: Guideline supply chain management in electronics manufacturing. ZVEI - German Electrical and Electronic Manufacturers Association (2014). https://www.zvei.org/fileadmin/user upload/Presse und Medien/Publikationen/2014/november/Guideline Supply Chain Management in Electronics Manufacturing/Guideline-Supply-ChainManagement.pdf. Accessed Jan 2019.

[4] Perkins, B., Wailgum, T.: What is supply chain management (SCM)? Definitions and best practices. CIO from IDG Commun., August 2017. https://www.cio.com/article/2439493/supply-chain-management/supplychain-management-supplychain-management-definition-and solutions.html. Accessed Jan 2019

[5] Byrne, R.O.: How AI helps build the supply chain that thinks for itself. Logistics Bur. https://www.logisticsbureau.com/how-ai-helps-build-thesupply-chain-thatthinks-for-itself/. Accessed Jan 2019.

[6] Irem Islek, Sule Gunduz Oguducu, "A Decision Support System for Demand Forecasting based on Classifier Ensemble", Communication papers of the Federated Conference on Computer Science and Information Systems, Vol. 13, 2017, pp. 35-41.

[7] HaixiaSang's "A dynamic modeling simulation for supply chain management inventory service: a case study on a rental housing unit manufacturing and logistics company" Conference: the 2018 International Conference August 2018

[8] ChristophFlöthmann, Kai Hoberg "Competency requirements of supply chain planners and analysts and personal preferences of hiring managers" November 2018.

[9] Yuchen Weng, Xiujuan Wang, Jing Hua, Haoyu Wang, Mengzhen Kang, Fei-Yue Wang, "Forecasting Horticultural Products Price Using ARIMA Model and Neural Network Based on a Large-Scale Data Set Collected by Web Crawler", IEEE Transactions on Computational Social Systems, Volume: 6, Issue: 3, 2019.

[10] Mandeep Mittal, Prabodh Ranjan Swain,, Hemant Rana, "A Nature Inspired Optimisation Method for Supply Chain Management Problem ", Amity International Conference on Artificial Intelligence (AICAI), IEEE, 2019. 